\title{
Study on Comprehensive Economic Contribution Caused by Development of the Natural Heritage Scenic Spot__Taking World Heritage Site Danxia Mount as an Example
}

\author{
Liu $\mathrm{Yi}^{1} \&$ Zhang Mengfan ${ }^{1}$ \\ ${ }^{1}$ Department of Tourism Management, College of Management, Jinan University, P. R.China \\ Correspondence: Zhang Mengfan, Department of Tourism Management, College of Management, Jinan \\ University, P. R.China. E-mail: 839905283@qq.com
}

Received: December 14, 2016

Accepted: January 17, 2017 Online Published: February 22, 2017

doi:10.5539/ijbm.v12n3p214

URL: https://doi.org/10.5539/ijbm.v12n3p214

\begin{abstract}
Despite the rising status of tourism industry, most of scenic spots are lack of innovation in tourism developing patterns, and tickets economy still dominate most of the region's tourism development. Based on this background, this paper taking world heritage site Danxia Mount as an example, using input-output analysis method, introducing the theory of lateral effect, has build structure tree model for multiplier effect of consumption in scenic spot. According to the tree model, multiplier effect of consumption in natural heritage scenic spot include industry spreading effect transmitted by endogenetic route and lateral effect transmitted by exogenous route. On the basis of research results, this paper gives suggestions to government on public tourism resources of scenic spots about how to choose appropriate tourism development pattern and make reasonable price policies of scenic spots.
\end{abstract}

Keywords: The world heritage scenic spot, Comprehensive contribution, Multiplier effect, Lateral effect, Input-Output

\section{Introduction}

With the sustained growth of domestic residents' travel demand and the expanding scale of the tourism industry, tourism has developed into a multiple-aspect, multi-dimensional comprehensive modern industry. The growth is causing a stronger pull effect on promoting social consumption, employment and the development of related industry, and it is also driving national economy increased substantially. However, many places are lack of innovation in tourism development patterns, and unilaterally conceive of tickets economy still dominated most of scenic spots, so the ticket prices of some world heritage scenic spots have been much higher than the developed countries, which are widely criticized by society. In stark contrast to this, West Lake open to the public for free now, and it has brought great economic benefits and social benefits to Hangzhou. How to evaluate the comprehensive contribution of scenic spots to tourist destination relying on resources? Academics have been lack of in-depth study, so ultimately results that both tickets economy pattern and West Lake free pattern have failed to get support of the tourism economic theory, which make the government lack theoretical guidance long-term on price policy of heritage tourism scenic spots.

This paper will theoretically explain tourism economic effect mechanism of action and diffusion paths caused by ticket consumption of the natural heritage scenic spot and quantitative research comprehensive multiplier effect of ticket consumption on the destination economy. In order to lead further broaden theory field of tourism multiplier effect, make its focus expand from tourism to tourism relevant industry, this paper provides theoretical references at choosing appropriate tourism development pattern, making reasonable scenic spot price policy and realizing optimization of economic benefits and social benefits for public tourism resources scenic destination government.

\section{Literature Review}

Modern tourism multiplier theory mainly has developed along the Keynesian multiplier model and the Leontief input - output model. But marginal propensity suggests it is difficult to calculate in reality, so Keynesian multiplier model has very little actual application value. Academic research about tourism multiplier is evolved essentially based on input-output model. 
Many scholars use input-output model to calculate the correlation effect and spread effects of tourism industry. Li Jiangfan and Li Guanlin quantitative researched the correlation effect and spread effects of Guangdong tourism (Li, 2001; Liu, 2005; Song, 2007; Liu, 2011). Wu (2012) studied the correlation effect of Chinese tourism one after another, Zhang (2006), Li (2006), Wang (2008), Cui (2010) respectively analyzed the correlation effect and spread effects of tourism in Urumqi, Chongqing, Xinjiang, and Zhejiang. Liu used input-output model to quantitative compared the spread effects between travel agency industry, hotel industry, and the scenic area management industry in China (Liu, 2010). Wang Qiyan analyzed industry association function of tourism and exhibition industry in the perspective of industrial convergence (Wang, 2014).Cheng Ruifang summarized the research about correlation effect of domestic tourism industry (Cheng, 2015).

American economist Rostow expounded the spreading effect of dominant industry and first proposed the concept of the lateral effect]. Liu (2003) think that in order to answer real economic problems comprehensively and correctly, we must start from the basic principle of input and output multiplier, clarify diffusion paths of input and output multiplier, and take the lateral effect of final product into consideration. Lateral effect refers to the increased of some kind of consumer goods (or investment/export),may lead to another kind of consumer goods increased (or investment/export). For example, the consumption of scenic spot tickets can trigger the accommodation and catering consumption. The concept of lateral effect opens up a new train of thought about industry correlation research, but due to the input and output table doesn't have ready-made data needed by lateral effect research, and industry characteristics are different in various sectors, current industry economics research has not carried out in-depth study on lateral effect. At present, the research about lateral effect mainly stay in the description of its features. Although the research about lateral effect has not been widely carried out, tourism is still a typical comprehensive consumption industry, so the literal effect can reflect the comprehensive property of tourism industry more in reality relative to spread effect, especially as tourist attractions, scenic spot tickets consumption's literal effect is more apparent.

At present, however, research about economic contribution of tourist attraction still limited in a single path of spread effect, but literal effect of tourism consumption, especially consumption of scenic spot tickets has not yet been incorporated into the research angle of view. Therefore, this paper taking world heritage site Danxia Mount as an example, using input-output analysis method, introducing the theory of lateral effect, exogenous revealed the comprehensive contribution of scenic spot consumption to regional economic from endogenetic route and exogenous route.

\section{Model Specification and Research Design}

\subsection{Model Specification}

The structure tree model for multiplier effect of consumption in scenic spots include industry spreading effect transmitted by endogenetic route and lateral effect transmitted by exogenous route. Endogenetic route is focusing on internal relation of industrial sector, performing as spreading effect of scenic area management industry through industrial relationship. Exogenous route is focusing on the external relations of tourism consumption, performing as lateral effect of tickets consumption. The function of two routes have reflected to comprehensive multiplier effect of consumption in scenic spots through direct effect and indirect effect (Figure 1).

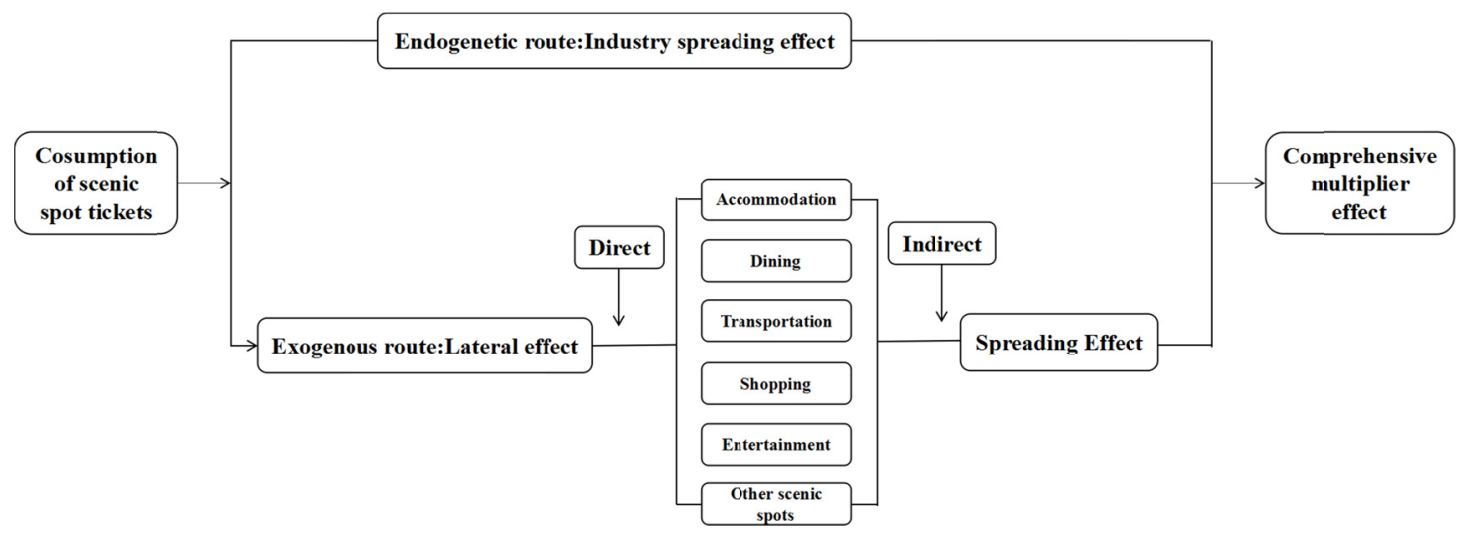

Figure 1. Structure tree model for multiplier effect of consumption in scenic spot 


\subsection{Research Design}

\subsubsection{Research Object}

This article takes the world heritage site Danxia Mount as an example, mainly considering that world heritage site have typical tourist attraction properties, which can help to eliminate the effect of other factors except scenic spot on travel behavior, and in this way, our research conclusion will have more reference value for tourist destination relying on resources to choose tourism development pattern in science. In addition, natural heritage scenic and cultural heritage scenic belong to different departments in the input-output table, so in order to calculate conveniently, we take natural heritage scenic as research object.

\subsubsection{Research Method}

According to the structure tree model for multiplier effect of consumption in scenic spots, calculation of scenic spots consumption multiplier effect includes spreading effect transmitted by endogenetic route and lateral effect transmitted by exogenous route. Spreading effect is calculated by input-output analysis according to the latest input-output table; Lateral effect include direct lateral effect and indirect lateral effect. Direct lateral effect calculation need to identify other tourism consumption structure caused by tickets consumption, so we solve this problem by tourist sample survey. The calculation of indirect lateral effect is same as spreading effect.

\subsubsection{Data Sources and Instructions}

The data sources in this paper includes tourist sample survey and official statistics. The research group went to Danxia Mount to conducted questionnaire survey in March 2016. The contents of questionnaire include basic statistics and consumption structure, and respondents include team tourists and individual tourists. 400 questionnaires were distributed and 336 effective questionnaires were taken back, so the rate of effective questionnaire is $84 \%$. Among them, the team tourists accounted for $23.45 \%$, the individual tourists accounts for $76.55 \%$. Official statistics are divided into two categories. One is 2012139 department input-output table of Guangdong, another is the number of tourists and the proportion of team tourists and individual tourists in 2015 provided by Danxia Mount. There are 272.86 millions of tourists in Danxia Mount, of which team tourists accounted for $13.66 \%$, and individual tourists accounted for $86.34 \%$.

\section{Data Analysis}

\subsection{Direct Contribution}

In the year of 2015, there are 272.86 millions of tourists in Danxia Mount, and the ticket revenue are 387.68 million yuan. Using input-output analysis method, we can measure that the added value of tickets in 2015 are 210.72 million yuan, accounting for 2.2\% of GDP in Renhua. These are direct contribution of Danxia Mount scenic spot tickets consumption to the local economy.

\subsection{Indirect Contribution}

\subsubsection{Spreading Effect Transmitted by Endogenetic Route}

Industrial spread refers to the process that in the national economy industry system, the change of some industry causes other direct related industries' change, then lead to indirectly related industries' change, handing on this way, till influence reduce gradually. The influence of industrial spread on the national economy industry system is spreading effect.

Using the concept of matrix of total consumption coefficient, based on relevant data and calculation formula of 2012 input-output table of Guangdong, as well as the number of tourists in 2015 provided by Danxia Mount and average spend of tourists measured by sampling survey, we can calculate that the endogenetic route output multiplier of Danxia Mount in 2015 is 0.82 , that is to say, every time the scenic spot increase 1 unit of the final product, the other industries of national economy will increase 0.82 units of the final product.

\subsubsection{Lateral Effect Transmitted by Exogenous Route}

\section{(1) Direct Lateral Effect}

This research taking world heritage site Danxia Mount as an example, calculated the literal effect of scenic spots consumption. Firstly we calculate direct literal effect. Through field investigation about tourist consumption structure of Danxia Mount, the scenic spot consumption lead to catering, accommodation, shopping, transportation, entertainment, and other kinds of consumption. According to sampling survey, we can get average spend and consumption structure of tourists in Danxia Mount. At the same time, according to the number of tourists in Danxia Mount in 2015 and value-added rate of each department in 2012 input-output table of Guangdong, we calculated total cost of tourists and corresponding added value. According to the calculation 
results, the scenic spot consumption will lead to many other relevant departments' consumption, and the department of transportation, accommodations are the most. In order to reflect the leading role of scenic spot consumption more intuitively, we need to calculate direct literal effect multiplier of every department and comprehensive direct literal effect multiplier. According to the concept of direct literal effect, results are shown in Table 1.

Table 1. Direct lateral effect multipliers of relevant departments caused by consumption of Danxia Mount

\begin{tabular}{lll}
\hline $\begin{array}{l}\text { Consumption } \\
\text { items }\end{array}$ & Industrial sector & Direct lateral effect multiplier \\
\hline \multirow{2}{*}{ Shopping } & Agricultural products & 0.88 \\
& $\begin{array}{l}\text { Vegetables, fruits, nuts and other } \\
\text { processed agricultural products }\end{array}$ & 0.07 \\
& Cultural industrial art, sports and ent & \\
& ertainment Goods & 0.11 \\
& Refined petroleum and nuclear fuel & 0.24 \\
Transportation & Railway transport & 0.38 \\
& Road transport & 0.62 \\
Dining & Air Transport & 0.17 \\
Accommodation & Dining & 1.01 \\
Entertainment & Eccommodation & 1.21 \\
Other scenic spot & Management for public facilities & 0.87 \\
Comprehensive direct lateral effect multiplier & 0.16 \\
\hline
\end{tabular}

The direct literal effect multiplier of Danxia Mount consumption to shopping, transportation, catering and accommodation is greater than 1, that is to say, the contribution of shopping, transportation, catering and accommodation consumption caused by scenic spot consumption has already exceeded scenic spot consumption itself. Among them, the direct literal effect multiplier of transportation and accommodation is 1.41 and 1.21, which are the highest. In shopping consumption, the direct literal effect multiplier of agricultural products is highest, reached to 0.88 . The comprehensive direct literal effect multiplier is as high as 5.72 , that is to say, every time the scenic spot increase 1 unit of the final product, the other industries of national economy will increase 5.72 units of the final product by direct literal effect, which means that the direct literal effect of scenic spot consumption is very significant.

\section{(2) Indirect Lateral Effect}

In addition to direct literal effect, other departments consumption caused by scenic spot consumption will also have corresponding spreading effect, this is indirect literal effect. From above analysis, according to the formula, we can calculate corresponding added value of the total cost of each department, indirect added value caused by direct output, and corresponding indirect literal effect multiplier. The calculation results are shown in Table 2 .

Table 2. Indirect lateral effect multipliers of relevant departments caused by consumption of Danxia Mount

\begin{tabular}{|c|c|c|c|c|c|}
\hline $\begin{array}{l}\text { Consumption } \\
\text { items }\end{array}$ & Industrial sector & $\begin{array}{l}\text { value added of Total } \\
\text { expenditure } \\
\text { (Unit: Ten thousand } \\
\text { Yuan) }\end{array}$ & $\begin{array}{l}\begin{array}{l}\text { Indirect value added } \\
\text { caused by direct } \\
\text { output }\end{array} \\
\text { (Unit: Ten thousand } \\
\text { Yuan) }\end{array}$ & $\begin{array}{l}\text { Indirect } \\
\text { multiplieı }\end{array}$ & lateral effect \\
\hline \multirow[b]{2}{*}{ Shopping } & Agricultural products & 18528.3 & 7639.0 & 0.36 & \multirow[b]{2}{*}{1.08} \\
\hline & $\begin{array}{l}\text { Vegetables, fruits, nuts } \\
\text { and other processed }\end{array}$ & 1424.3 & 4455.5 & 0.21 & \\
\hline
\end{tabular}




\begin{tabular}{|c|c|c|c|c|c|}
\hline & agricultural products & & & & \multirow{11}{*}{2.45} \\
\hline & $\begin{array}{l}\text { Cultural industrial art, } \\
\text { sports and entertainme } \\
\text { nt Goods }\end{array}$ & 2300.6 & 10811.2 & 0.51 & \\
\hline \multirow{4}{*}{ Transportation } & $\begin{array}{l}\text { Refined petroleum and } \\
\text { nuclear fuel }\end{array}$ & 5059.2 & 18674.6 & 0.89 & \\
\hline & Railway transport & 8012.8 & 6438.7 & 0.31 & \\
\hline & Road transport & 13001.4 & 11066.2 & 0.53 & \\
\hline & Air Transport & 3535.7 & 15256.9 & 0.72 & \\
\hline Dining & Dining & 21329.6 & 23395.0 & 1.11 & \\
\hline Accommodation & Accommodation & 25418.6 & 35725.6 & 1.70 & \\
\hline Entertainment & Entertainment & 18269.3 & 11743.7 & 0.56 & \\
\hline Other scenic spots & $\begin{array}{l}\text { Management for public } \\
\text { facilities }\end{array}$ & 3411.2 & 2781.9 & 0.13 & \\
\hline \multicolumn{4}{|c|}{ Comprehensive indirect lateral effect multiplier } & 7.03 & \\
\hline
\end{tabular}

The Table 3 shows that the indirect literal effect multiplier of Danxia Mount consumption to shopping, transportation, catering and accommodation is greater than 1, it means that the indirect contribution of shopping, transportation, catering and accommodation consumption caused by scenic spot consumption also has already exceeded scenic spot consumption itself. Among them the direct literal effect multiplier of transportation and accommodation is 2.45 and 1.70 , which are the highest. In shopping consumption, the indirect literal effect multiplier of arts and crafts is highest, reached to 0.51 . The comprehensive indirect literal effect multiplier is as high as 7.03, that is to say, every time the scenic spot increase 1 unit of the final product, the other industries of national economy will increase 7.03 units of the final product by indirect literal effect, which means that the direct literal effect of scenic spot consumption is also very significant, and exceeded direct literal effect.

\subsection{Comprehensive Contribution}

In conclusion, through the case study of Danxia Mount, the structure tree model for multiplier effect of consumption in scenic spot build initially in this paper is showed specifically and intuitively in the transmission route and transmission strength of scenic spot consumption multiplier effect (Figure 2).

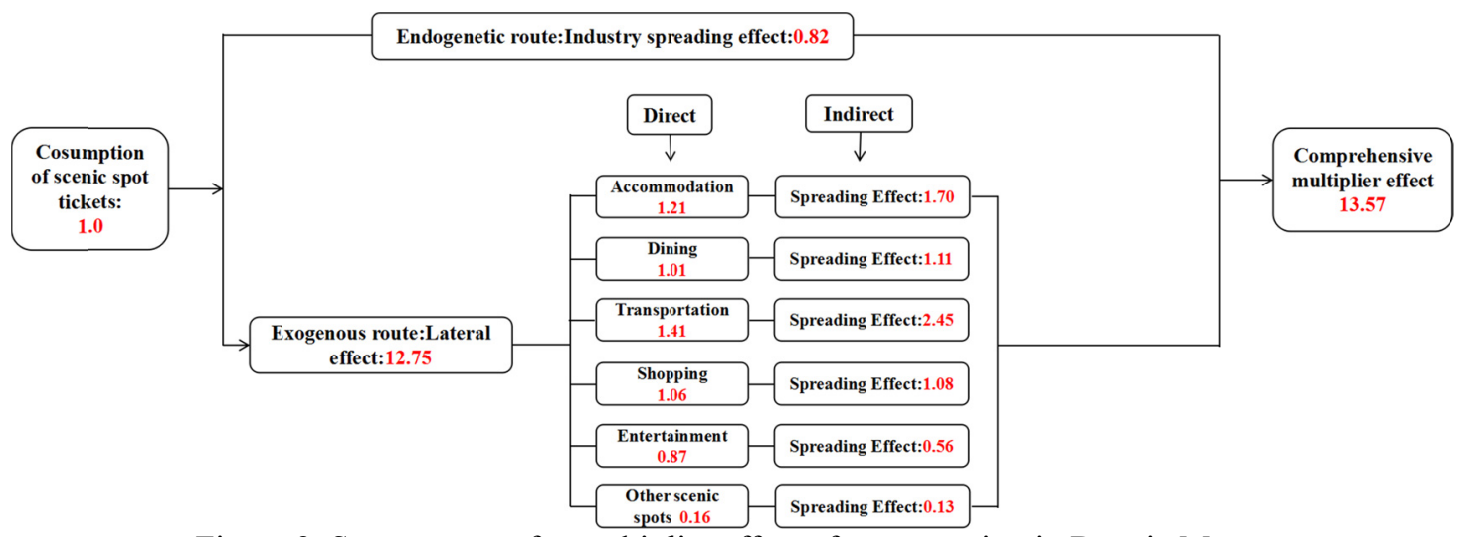

Figure 2. Structure tree for multiplier effect of consumption in Danxia Mount

The Figure 2 shows that the multiplier effect of the scenic spot consumption can be divided into industry spreading effect transmitted by endogenetic route and lateral effect transmitted by exogenous route. 1 unit of the scenic spot final product can only drive the other industries of national economy increased 0.82 units of the final product by endogenetic route. However, every time the scenic spot increase 1 unit of the final product, the other industries of national economy will increase 12.75 units of the final product by exogenous route. Exogenous path multiplier is 15.5 times of the endogenous path multiplier effect, which means that the literal effect of Danxia 
Mount consumption is extremely huge. Among that the literal effect of accommodation' influence is 2.99, which is the biggest. The second is the catering sector, multiplier effect is 2.12 . The comprehensive multiplier effect of Danxia Mount is as high as 13.57, which means that as a world natural heritage scenic, Danxia Mount is extremely significant for the local economy as a leading role.

\section{Conclusion}

\subsection{Research Conclusions}

This study is taking world heritage site Danxia Mount as an example, through field investigation, using input-output analysis method, quantitatively researched the natural heritage scenic spot' comprehensive contribution to regional economy, and got following conclusions:

Firstly, the multiplier effect of ticket consumption affected local economy by spreading effect transmitted by endogenetic route. The endogenetic route output multiplier of Danxia Mount in 2015 is 0.82 , that is to say, every time the scenic spot increase 1 unit of the final product, the other industries of national economy will increase 0.82 units of the final product. Therefore, only tickets consumption motivational role to local national economy is very limited.

Secondly, the multiplier effect of ticket consumption also can drive other industries' consumption by lateral effect transmitted by exogenous route, and then indirectly promote the growth of national economic by spreading effect. Literal effect can be divided into direct literal effect and indirect literal effect. The results show that the comprehensive direct literal effect multiplier is 5.72. Among them the contribution of shopping (1.06), transportation (1.41), catering (1.01) and accommodation (1.21) consumption caused by scenic spot consumption has already exceeded scenic spot consumption itself. The comprehensive indirect literal effect multiplier is 7.03. Among them the spreading effect of shopping (1.08), transportation (2.45), catering (1.11) and accommodation (1.70) consumption caused by scenic spot consumption has also exceeded scenic spot consumption itself. The comprehensive literal effect of Danxia Mount is as high as 12.57, which is extremely huge.

Thirdly, the structure tree model for multiplier effect of consumption in scenic spots build initially in this paper deeply reveals the transmission route and transmission strength of scenic spot consumption multiplier effect. The transmission route including spreading effect transmitted by endogenetic route and lateral effect transmitted by exogenous route. The endogenetic route output multiplier of Danxia Mount in 2015 is 0.82 , while the comprehensive literal effect multiplier transmitted by exogenous route is as high as 12.57 , which is 15.5 times of endogenetic route output multiplier. This shows the main multiplier effect of scenic spot consumption is realized by exogenous route. The comprehensive multiplier effect of Danxia Mount is as high as 13.57, which means that as a world natural heritage scenic, Danxia Mount is extremely significant for the local economy as a leading role.

\subsection{Research Enlightenment}

On the basis of research results, this paper makes following suggestions for governments of public tourism resources scenic destination about how to choose appropriate tourism development pattern and make reasonable price policies to scenic spot:

Firstly, the natural heritage sites should control the ticket price reasonably, and gradually get rid of the thinking of tickets economy. According to the results, the literal effect of tickets consumption's contribution to the local economy is far greater than scenic spots tickets consumption itself. As for spreading effect, the motivational role of scenic spot sector itself is not that obvious, and well below the industry average. Therefore, relevant administrative departments of Natural heritage scenic spots should control the ticket price, and appropriately lower the price of tickets when necessary, to facilitate tourists for shopping, catering, accommodation and other projects of consumption, and stimulate local economic developed better.

Secondly, the natural heritage sites should strongly support the development of local characteristic accommodation, catering and shopping, and actively promote the literal effect of scenic spots consumption. The results show that the scenic spots consumption's contribution to the local economy mainly through the literal effect. Therefore, in order to preferably promote the development of local economy, relevant administrative departments of Natural heritage scenic and tourism destination government should make positive policy to vigorously support the development of local characteristic accommodation, catering and tourism products, offering a variety of product selection, and improving visitors' consumption level, especially tourism products; Government should encourage the development of characteristic agricultural and sideline products and souvenirs, in order to maximize the leading role of shopping to the local national economy. 


\section{References}

Cheng, R. F., \& Wang, W. H. (2015). An literature review of enterprise relationship in the China's tourist industry. Economic Forum, 3, 98-103.

Cui, F., \& Bao, J. (2010). An analysis of tourism industrial correlation and industrial spread effect in Zhejiang province.Tourism Tribune, 3, 13-20.

Li, J. F., Li, G, L., \& Jiang, B. (2001). An analysis of enterprise relationship and enterprise spread in the tourist industry-Taking Guangdong as an example. Tourism Tribune, 3, 19-25.

Li, W. K., Liu, J. P., \& Guo, Y. (2006). An analysis of enterprise spread in Chongqing tourist industry on the base of input-output analysis. Journal of Nanjing Xiaozhuang University, 4, 96-100.

Liu, L. Q., Zhao, L, M., \& Wang, L. Y. (2005). Analysis of the development of tourism in China. Journal of Tianjin University(Social Sciences), 3, 196-199.

Liu, X. X., Hu, X., \& Zhou, H. (2011). An analysis of the measurement of correlation of China's tourism industry and macroeconomic effects-Based on the perspective of input-output tables in 2002 and 2007.Tourism Tribune, 3, 31-37.

Liu, Y. (2010). An analysis of the evaluation of the impact of tourism industry on the expansion of the final consumption in our country and its countermeasures. Tourism Tribune, 9, 27-31.

Song, Z. W. (2007). A research on industrial correlation of China's tourism industry: Based on the input-output model. Tourism Science, 2, 7-12(78).

Wang, Q. Y., \& Xu, L. (2014). A study on fusion of tourism and exhibition industry in Beijing: Based on the perspective of industrial linkage. Modern Management Science, 12, 9-11.

Wang, Y., \& Wang, Z. (2008). An analysis on industrial correlation and spread of Xinjiang's tourism industry:Based on the input-output model. Journal of Arid Land Resources and Environment, 5, 112-117.

Wu, S. M. (2012). An analysis of enterprise relationship and enterprise spread in the China's tourist industry. Industrial Economics Research, 1, 78-86.

Zhang, Y., \& Song, L. (2006). On the industry relevance and industry spread of tourism in Urumqi. Journal of Xinjiang University (Philosophy Social Science), 1, 10-13.

\section{Copyrights}

Copyright for this article is retained by the author(s), with first publication rights granted to the journal.

This is an open-access article distributed under the terms and conditions of the Creative Commons Attribution license (http://creativecommons.org/licenses/by/4.0/). 